\title{
Khat Chewing among Students of Higher Education in Jazan Region, Saudi Arabia: Prevalence, Pattern, and Related Factors
}

\author{
Rashad Mohammed Alsanosy, ${ }^{1}$ Mohamed Salih Mahfouz, ${ }^{2}$ \\ and Abdelrahim Mutwakel Gaffar ${ }^{2}$ \\ ${ }^{1}$ Substance Abuse Research Center (SARC), Jazan University and the Department of Family and Community Medicine, \\ Faculty of Medicine, Jazan University, P.O. Box 114, Jazan, Saudi Arabia \\ ${ }^{2}$ Family and Community Medicine Department, Faculty of Medicine, Jazan University, P.O. Box 2531, Jazan 45142, Saudi Arabia
}

Correspondence should be addressed to Abdelrahim Mutwakel Gaffar; mutwakel73@gmail.com

Received 2 April 2013; Accepted 29 May 2013

Academic Editor: Satoshi Maruyama

Copyright (C) 2013 Rashad Mohammed Alsanosy et al. This is an open access article distributed under the Creative Commons Attribution License, which permits unrestricted use, distribution, and reproduction in any medium, provided the original work is properly cited.

Objectives. (1) To estimate the prevalence and behavioral patterns of Khat chewing and (2) to investigate factors that influenced the pattern of Khat use among undergraduate students in different higher education institutions in Jazan region, Saudi Arabia. Materials and Methods. A cross-sectional study using a pretested structured self-administered quantitative questionnaire was used to collect data. SPSS version 17 software program was used for data analysis. Results. The overall current Khat chewing prevalence among higher education students was found to be $23.1 \%$, significantly higher among males at $38.5 \%$ than among females at $2.1 \%$ $(P<0.001)$. Lifetime Khat chewer students were $24.8 \%$ for males at $40.5 \%$, significantly higher compared with females at $3.7 \%$ $(P<0.001)$. Univariate analysis revealed that the gender of student, smoking status of student, a friend's smoking, and Khat chewing were associated with a significant high risk of Khat chewing $(P<0.001$ for all $)$. Conclusions. The use of Khat trend is increasing among higher education students in Jazan region. A multilevel, value based, comprehensive, and strategic long-term intervention plan is needed. The comprehensive plan may include social interventions geared by creating recreations alternatives and opportunities for youth and a critical review for current authorities' interventions and services.

\section{Introduction}

Health is defined as a state of complete physical, mental, and social well-being and not merely absence of disease or infirmity [1]. The definition is applied to physical, mental, psychological, social, and spiritual aspects of the individual person. During the past forty years, there has been a growing concern regarding the risk factors associated with youth physical health and mental well-being [2]. Substance abuse is among the most risk-taking behaviors committed by the youth that result in serious life-threatening consequences such as incarceration, disease, and death $[3,4]$.

Khat chewing is a common habit among all segments of Jazan population. Khat chewing produces psychostimulation effect in the form of euphoria and excitement because of cathinone contents [5-7]. It is well documented that Khat has many severe public health and social problems [8-14]. In addition to the health problems associated with Khat use, Khat chewers spend considerable time in this habit; this time wasting affects the social and economic development of the country. Diversion of family income for purchase of Khat results in neglecting the family needs leading to family conflicts and discords. Many studies have demonstrated that there is a clear association between heavy consumption of Khat and psychosis [15-21].

Adolescence means the period of transition from childhood to adulthood during which they experience enormous physical, psychological, and sexual changes. The economic, social, cultural, and political environments in which they live either directly or indirectly influence these changes. 
This critical stage of the life cycle which adolescents go through needs information and services carefully tailored to meet their needs [6].

Few studies have been conducted in Jazan region focusing on Khat chewing practice among secondary and university students [5-7]. University-wide surveys are needed to highlight Khat chewing patterns and different risk factors that may contribute to adoption of the habit among Saudi youngsters, comparing students of different sexes, majors, and school education years. Thus, the objectives of this study were to estimate the prevalence and behavioural patterns of Khat use among undergraduate students at higher education institutions of Jazan region, Saudi Arabia, during the academic year 2011/2012 and to investigate different associated factors that contribute to Khat chewing habit among university students.

\section{Material and Methods}

2.1. Design and Study Participants. A cross-sectional study targeted students in the three higher education institutions of Jazan region; they are Jazan university, the Technical College, and the Academic Health College (Private). Jazan University is a leading institution in the region with 26 faculties enrolling more than 50,000 students. Jazan region is one of the thirteen regions of the Kingdom of Saudi Arabia. It is located on the tropical Red Sea coast in southwestern Saudi Arabia. Jazan covers an area of 11,671 square kilometers, including some 5,000 villages and towns. Attached to it are 100 islands, including the largest island of Farasan. Jazan region runs along the Red Sea coast for almost 200 miles $(300 \mathrm{~km})$. It is a highly populated state with a total population of 1.5 million.

2.2. Sampling. A representative sample of 4,100 students was calculated, based on an estimated prevalence of Khat chewing use in Jazan region of $25 \%$ [6]. The sample stratified first according to the three institutions and then according to colleges. Clusters of classes were taken from each stratum randomly. For execution of the sampling plan, the sampling frames for selection of study participants were prepared in consultation with the deanship of student affairs and respective faculties to obtain details of classes and number of students in each faculty. Probability proportional to size sampling (PPS) was used to determine the number of students in the different faculties.

2.3. Data Collection. A questionnaire was developed by reviewing the relevant literature and previously used standardized instruments and protocols $[6,7]$. It contained 75 questions, most of which were closed-ended with precoded responses. The questions were divided into four sections: (i) sociodemographic backgrounds; (ii) Khat chewing habit; (iii) smoking and other substances; and (iv) attitudes towards Khat and smoking. The questionnaire was pretested in two selected colleges, and appropriate revisions were made before being used for actual data collection.

The questionnaires were distributed and collected by class student's leaders under supervision of reaching assistants. The anonymity of subjects was emphasized and confidentiality strictly maintained on all collected study questionnaires. The operational definitions used were (a) nonuser: a person who has never used Khat in any form, (b) lifetime/ever chewer: an individual is considered an ever chewer even if he/she had chewed only once in his/her lifetime and (c) current user: individuals who were chewing Khat within 30 days preceding the study.

2.4. Data Quality Control and Analysis. To ensure data collection quality, fieldwork supervisor reviews the submitted questionnaire daily, and any errors or inconsistency is reviewed immediately. The data entry stage was started immediately after data collection was finished. The data entry took place at Jazan Substance Abuse Research Centre (SARC) under the supervision of data analysis specialist. The data were entered into Epi Info version 3.5.3 and transferred to SPSS version 17 (SPSS Inc., Chicago, IL, USA). Double data entry was conducted to ensure high quality of data. Data analyze involved descriptive statistics as well as inferential statistics. Descriptive statistics involved simple tabulation, frequencies, and proportion for categorical variables including crosstabulations. Differences in proportions were compared for significance using chi-square test, with significance level set at $P<0.05$. Also, multivariate logistic regression analyses were used to identify factors associated with Khat use by controlling for the effect of potential confounding variables. Khat chewing status was set as a dependent variable, while the following factors were included in the model as independent variables: gender, faculty type, class, smoking status, friend's smoking and Khat chewing status, and father's and brother's Khat chewing status. Adjusted odds ratios (ORs) and their 95\% confidence intervals were reported. Hosmer-Lemeshow statistics was used to evaluate the goodness of the fit of the model.

2.5. Ethical Clearance. Ethical clearance was obtained from Jazan University Ethical Committee. Authorization was granted from his Excellency Vice-Chancellor of Jazan University and the deans of the respective colleges and faculties. Consent was granted from participating students during distribution of the questionnaire, and students were informed that the information collected will be kept anonymous and participation is totally voluntary.

\section{Results}

The overall response rate for distributed questionnaires was $91.80 \%$ (3764 from the target of 4100 students), but not all questions were attempted equally by all participants. The mean, median, and mode of students ages were 20.8, 21.0, and 20.0 years, respectively, with $(\mathrm{SD}=1.5)$, which indicates a normal distribution of the participants ages. As shown in Table 1, $57.5 \%$ of students were males compared with $42.5 .5 \%$ females. Most sampled students were single (86.5\%). One-quarter of the students were from health-related colleges (24.7\%), while students from the other two groups Arts and Humanities and other science colleges were $36.7 \%$ and $38.6 \%$, respectively, which represent the actual student distribution in higher education institutions in Jazan. Health-related colleges includ 
medicine, dentistry, pharmacy and applied medical sciences; other scientific colleges involved science, scientific specialization of education faculties, and computer science. The third category Arts and Humanities included arts, education, language and translation, administrative sciences, and Sharia and law. With regard to the area of residence, most students (58.8\%) were from urban background and the remaining (41.2\%) from rural areas (Table 1). The parental education of the respondents revealed that $38.8 \%$ of the mothers and $14.8 \%$ of the fathers were reported to be illiterate, with only $11.6 \%$ of the mothers and $27.1 \%$ of the fathers with university degree or above (Table 1).

Table 2 provides the lifetime and current prevalence of Khat chewing among study participants; the overall current Khat chewing prevalence among students was found to be 23.1\% (95\% CI: 21.7-24.4), significantly higher among males at $38.5 \%$ (95\% CI: 36.5-40.5) than among females $2.1 \%(95 \%$ CI: 1.6-2.9) $(P<0.001)$. The same indicator was found to be significantly lower for urban students at $22.2 \%$ compared with $28.6 \%$ for rural students $(P<0.001)$. The current Khat chewing prevalence among scientific colleges, health-related faculties, and Arts and Humanities, 29.7\%, 23.5\%, and 15.8\% respectively.

Lifetime Khat chewers students were $24.8 \%$ (95\% CI: 23.4-26.2), for males at 40.5\% (95\% CI: 38.4-42.5) also significantly higher compared with females $3.7 \%$ (95\% CI: 4.39-6.53) $(P<0.001)$. The lifetime prevalence of Khat chewing rate for rural students was $26.5 \%$, significantly different from urban students $20.6 \%(P<0.05)$. The ever Khat chewing prevalence was found to be $23.5 \%$ in health related colleges, compared with $15.8 \%$ and $23.1 \%$ for Arts and Humanities and other science colleges.

Table 3 shows patterns of Khat chewing among both male and female students. It is clear from the table that the majority of students chew Khat in their houses followed by friend's house with significant difference between male and female responses $(P<0.001)$; more than $50 \%$ of females chew Khat in their houses compared with $36.9 \%$ of boys. Although Khat is banned by the government, the majority of participants $(89.1 \%)$ argued that it is easy $(38.9 \%)$ or to some extent easy $(50.2 \%)$ to obtain Khat; no significant difference was observed between males and females responses $(P>0.05)$. Almost $53.7 \%$ of students buy Khat directly from sellers; $54.8 \%$ of boys buy it, while $29.4 \%$ of girls said that they take some from another person $(P<0.001)$. Students did not show different responses regarding age at first time of Khat chewing; the majority (63.5\%) reported that they started chewing Khat after the age of 15 years. Regarding the frequency of Khat chewing, 78.3\% said that they chew Khat in social occasions only, while $29.3 \%$ of the girls chew Khat at a daily bases, and $36.6 \%$ of the boys chew Khat at weekends $(P>0.001)$. When students were asked about timing of Khat chewing, $78.3 \%$ of them reported that they chew Khat at night with significant difference between boys and girls $(P<0.001)$ as $23.8 \%$ of girls prefer to chew Khat at noon; only $8.1 \%$ of boys chew Khat at the same time. Further, there is a significant difference between male and female responses regarding with whom do they chew Khat, time spent in Khat chewing session, and motives for Khat chewing
TABLE 1: Some selected background characteristics of the study population.

\begin{tabular}{|c|c|c|}
\hline Characteristics & $N$ & $\%$ \\
\hline \multicolumn{3}{|l|}{ Gender $(n=3764)$} \\
\hline Male & 2165 & 57.5 \\
\hline Female & 1599 & 42.5 \\
\hline \multicolumn{3}{|l|}{ Age groups $(n=3217)$} \\
\hline Less than 20 years & 614 & 16.3 \\
\hline $20-21$ & 1606 & 42.7 \\
\hline $22-23$ & 830 & 22.1 \\
\hline 24 and above & 167 & 4.4 \\
\hline \multicolumn{3}{|l|}{ Colleges $(n=3764)$} \\
\hline Health related & 931 & 24.7 \\
\hline Arts and humanities & 1380 & 36.7 \\
\hline Other scientific & 1453 & 38.6 \\
\hline \multicolumn{3}{|l|}{ Mode of living } \\
\hline Rural & 1549 & 41.2 \\
\hline Urban & 2215 & 58.8 \\
\hline \multicolumn{3}{|l|}{ Marital status $(n=3764)$} \\
\hline Married & 341 & 9.1 \\
\hline Single & 3255 & 86.5 \\
\hline Divorced & 44 & 1.2 \\
\hline Widowed & 5 & 0.1 \\
\hline \multicolumn{3}{|c|}{ Father's education $(n=3764)$} \\
\hline Illiterate & 557 & 14.8 \\
\hline Primary & 981 & 26.1 \\
\hline Intermediate & 595 & 15.8 \\
\hline Secondary & 521 & 13.8 \\
\hline University and above & 1021 & 27.1 \\
\hline \multicolumn{3}{|c|}{ Mother's education $(n=3764)$} \\
\hline Illiterate & 1459 & 38.8 \\
\hline Primary & 1068 & 28.4 \\
\hline Intermediate & 419 & 11.1 \\
\hline Secondary & 306 & 8.1 \\
\hline University and above & 437 & 11.6 \\
\hline
\end{tabular}

$P$ value $=0.000,0.023$, and 0.000 , respectively. Almost 62.3\% of students spend between (5 and 9) hours in Khat session, and $70.1 \%$ of them chew Khat with their friends, while approximately $50 \%$ chew Khat when they feel they need to change their mood.

The results of the univariate and multivariate logistic regression analyses for potential risk factors of Khat chewing are shown in Table 4. Univariate analysis revealed that gender of student, smoking status of student, friend's smoking and Khat chewing, and father's and brother's Khat chewing status were associated with a significant high risk of Khat chewing $(P<0.001$ for all $)$, students' smoking status $(\mathrm{OR}=20.69$, $P<0.001)$, gender $(\mathrm{OR}=17.7, P<0.001)$, friend using Khat $(\mathrm{OR}=17.13, P<0.001)$, friend using tobacco $(\mathrm{OR}=$ $7.11, P<0.001)$, brother using Khat $(\mathrm{OR}=2.56, P<0.001)$, and father using Khat $(\mathrm{OR}=1.77, P<0.001)$. In the multivariate logistic regression analysis, students' smoking status $(\mathrm{OR}=18.25, P<0.001)$; gender $(\mathrm{OR}=10.10, P<0.001)$; friend using Khat $(\mathrm{OR}=4.52, P<0.001)$; brother using Khat 
TABLE 2: Prevalence of Khat chewing among study participants.

\begin{tabular}{lcccc}
\hline \multirow{2}{*}{ Category } & \multicolumn{3}{c}{ Ever Khat chewers } & \multicolumn{2}{c}{ Current Khat chewers } \\
& $N(\%)$ & $95 \% \mathrm{CI}$ & $N(\%)$ & $95 \% \mathrm{CI}$ \\
\hline Gender & & & & \\
$\quad$ Male & $876(40.5)^{* *}$ & $38.4-42.5$ & $834(38.5)^{*}$ & $36.5-40.5$ \\
$\quad$ Female & $59(3.7)$ & $2.9-4.9$ & $34(2.1)$ & $1.6-2.9$ \\
College Type & & & & \\
$\quad$ Health related & $221(23.7)$ & $21.1-26.5$ & $219(23.5)$ & $20.9-26.3$ \\
$\quad$ Arts and humanities & $248(18.0)$ & $16.0-20.0$ & $218(15.8)$ & $18.9-17.8$ \\
$\quad$ Other scientific & $466(32.1)$ & $29.7-34.5$ & $431(29.7)$ & $27.3-32.0$ \\
Mode of living & & & & \\
$\quad$ Rural & $443(28.6)^{*}$ & $26.4-30.9$ & $441(26.5)^{*}$ & $24.3-28.8$ \\
$\quad$ Urban & $492(22.2)$ & $20.5-23.9$ & $457(20.6)$ & $18.9-22.3$ \\
\hline Total & $935(24.8)$ & $23.4-26.2$ & $868(23.1)$ & $21.7-24.4$ \\
\hline
\end{tabular}

${ }^{*}$ Significant difference $(P$ value $<0.05),{ }^{* *}$ significant difference $(P$ value $<$ $0.01)$.

$(\mathrm{OR}=2.65, P<0.001)$; father using Khat $(\mathrm{OR}=1.68, P<$ $0.05)$ remained as significant and independent predictors for Khat chewing among higher education students of Jazan region.

\section{Discussion}

Six years ago, the prevalence of current Khat chewing among college students in Jazan was $15.2 \%$ among males $[5,6]$ in spite of the efforts done by government and NGOs, the present study showed that the overall prevalence reaches $23.1 \%$ (38.5\% for males and $2.1 \%$ for females). The prevalence of Khat chewing among higher education students is less than that observed among general population in Jazan, Yemen, Ethiopia, and Somalia [7, 17, 22, 23]. Among Aden University medical students in Yemen, 54\% chew Khat [22]. Similar prevalence of rate of current use of khat $(22.3 \%)$ was reported in Ethiopia among medical and paramedical students in a college in northwestern Ethiopia [23] and among 20.4\% among students in southwestern Uganda [24]. Lifetime Khat chewing prevalence in the current study was $24.8 \%$ (males $40.5 \%$, females $3.7 \%$ ) which is similar to that reported in Jazan previously [6] and lower than that reported in Ethiopia [23]. The use of Khat (current and lifetime) was significantly higher among males and rural residents; similar results about the residents were reported in Jazan previously and Ethiopia $[6,25]$.

Although Khat trading is illegal in Saudi Arabia, and since 2006 a new more strict legal system was implemented, it seems to have no effect, because there is an observed rising trend in Khat use among higher education students, and it can be contributed to the availability of Khat and easiness to get it. The majority of the participants-almost $90 \%-$ stated that it is easy or to some extent easy to get Khat. Jazan region is bordering Yemen and across the Red Sea in Ethiopia, Somalia, and Kenya where Khat production and trading is legal [26], and smuggling is difficult to control. During the period 2009-2011 the "Al Hothian war" north of Yemen affected the "accessibility" and "increased the cost," as believed by many people in Jazan.
Also Faifa mountain area in Jazan is famous for Khat production. The government prohibits the expansion of khat cultivation in Faifa mountain and established Faifa Development Authority since 1978 under the supervision of the Ministry of Interior to control Khat cultivation and support farmers to replace Khat with alternative crops, such as fruit and coffee trees [6]. The progression of such intervention need to be assessed because Khat is still cultivated in Faifa, and strengthening of mechanisms for law enforcement is needed to minimize the availability of Khat in the community.

The pattern of Khat use among higher education students is not restricted by social regulation mechanisms, and even, it is a social norm. It is an acceptable and socialization practice; only $8 \%$ of users chew Khat alone, while the rest use Khat with their family members, relatives, and friends [27]. Female use pattern is significantly different from male users regarding the partners (Table 3), Khat source, place, chewing time, and duration. Females tend to use Khat more with family and relatives, get it from another person, use it at home at noon, and chew for less than five hours, while males use khat more frequently with friends, purchase it, use it at friends' houses and public places at night, and chew for more than five hours. Those who spend less than 5 hours chewing Khat were $25.2 \%$, while it was $48.2 \%$ in 2006 [5]. Understanding these different patterns of Khat use is important when planning community intervention programs to reach users.

Alcohol and drugs use in different cultural backgrounds share a common hypothetical causal mechanism. "Killing time" is the similar function of drugs and alcohol use across groups which involve countering the psychosocial distress and uncertainties about the future as well as past trauma [28]. People use Khat for similar reasons: when they need to change their mood (49\%) and feel stressed (8.8\%). Khat is used usually for social recreation; motor vehicle drivers and truck drivers in Ethiopia chew khat during long distance driving to keep awake. During examination periods, a significant portion of students chew khat to be alert. To reduce physical fatigue is one of the functions that craftsmen and farmers use khat for, and traditional healers use it to heal ailments [29]. Generally, many social determinants interact with khat use. The monotony of life/work which leads to behaviors for "killing time" along with heavy academic load forces students to use this stimulant as reported in other countries.

In a study among Yemeni Khat consumers, they argue that khat improves relationships in Yemeni society, is the best way to spend one's time, leads to relief of social and mental stress, and improves sexual experience during intercourse [30]. The available alternatives for youth to spend their time are limited in the region. Thus, options for entertainment, voluntary work, open spaces like parks and playgrounds, clubs, sport, and recreational activities are highly needed.

The most significant risk factors identified in this study (Table 4) were students' smoking status, male gender, having friend using Khat, brother using Khat, and father using Khat and are significant and independent predictors for Khat chewing among higher education students of Jazan region.

Similar factors are also reported as risk factors for tobacco use like friends, brothers due to peer pressure, and the influence of friends. 
TABLE 3: Pattern of Khat chewing among study participants according to gender.

\begin{tabular}{|c|c|c|c|c|}
\hline Characteristics & Male $N(\%)$ & Female $N(\%)$ & Total N (\%) & $P$ value \\
\hline \multicolumn{5}{|l|}{ Place of Khat chewing $(n=857)$} \\
\hline In my house & $299(36.9)$ & $25(53.2)$ & $324(37.8)$ & \multirow{6}{*}{0.000} \\
\hline In my friend's house & $215(26.5)$ & $10(21.3)$ & $225(26.3)$ & \\
\hline In school & $7(0.9)$ & $5(10.6)$ & $12(1.4)$ & \\
\hline In public places & $165(20.4)$ & $2(4.3)$ & $167(19.5)$ & \\
\hline In occasions & $25(3.1)$ & $0(0.0)$ & $25(2.9)$ & \\
\hline Other place & $99(12.2)$ & $5(10.6)$ & $104(12.1)$ & \\
\hline \multicolumn{5}{|c|}{ Do you think that it is easy to obtain Khat? $(n=862)$} \\
\hline Yes & $313(38.5)$ & $22(44.9)$ & $335(38.9)$ & \multirow{3}{*}{0.378} \\
\hline Yes to some extent & $413(50.8)$ & $20(40.8)$ & $433(50.2)$ & \\
\hline No & $87(10.7)$ & $7(14.3)$ & $94(10.9)$ & \\
\hline \multicolumn{5}{|l|}{ Khat source $(n=738)$} \\
\hline From sellers & $386(54.8)$ & $10(29.4)$ & $396(53.7)$ & \multirow{5}{*}{0.000} \\
\hline I give money to another person to buy it & $67(9.5)$ & $4(11.8)$ & $71(9.6)$ & \\
\hline I take some Khat from another person & $117(16.6)$ & $10(29.4)$ & $127(17.2)$ & \\
\hline Elder person gives me Khat & $55(7.8)$ & $5(14.7)$ & $60(8.1)$ & \\
\hline Other & $799(11.2)$ & $5(14.7)$ & $84(11.4)$ & \\
\hline \multicolumn{5}{|l|}{ Age at first time to chew Khat $(n=868)$} \\
\hline Less than 10 years & $67(8.0)$ & $4(11.8)$ & $71(8.2)$ & \multirow{3}{*}{0.653} \\
\hline $10-14$ years & $238(28.5)$ & $8(23.5)$ & $246(28.3)$ & \\
\hline More than 15 years & $529(63.4)$ & $22(64.7)$ & $551(63.5)$ & \\
\hline \multicolumn{5}{|l|}{ Khat chewing time $(n=847)$} \\
\hline At noon & $65(8.1)$ & $10(23.8)$ & $75(8.9)$ & \multirow{4}{*}{0.000} \\
\hline After noon & $66(8.2)$ & $4(9.5)$ & $70(8.3)$ & \\
\hline At evening & $38(4.7)$ & $1(2.4)$ & $39(4.6)$ & \\
\hline At night & $636(79.0)$ & $27(64.3)$ & $663(78.3)$ & \\
\hline \multicolumn{5}{|l|}{ Frequency of Khat chewing $(n=805)$} \\
\hline Daily & $57(7.5)$ & $12(29.3)$ & $69(8.6)$ & \multirow{4}{*}{0.005} \\
\hline Most of the weekdays & $86(11.3)$ & $8(19.5)$ & $94(11.7)$ & \\
\hline Weekends only & $280(36.6)$ & $9(22.0)$ & $289(35.9)$ & \\
\hline In occasions & $341(44.6)$ & $12(29.3)$ & $353(43.9)$ & \\
\hline \multicolumn{5}{|l|}{ Time spent in Khat session $(n=822)$} \\
\hline Less than 5 hours & $190(24.3)$ & $17(43.6)$ & $207(25.2)$ & \multirow{3}{*}{0.000} \\
\hline $5-9$ hours & $500(63.9)$ & $12(30.8)$ & $512(62.3)$ & \\
\hline More than 10 hours & $93(11.9)$ & $10(25.6)$ & $103(12.5)$ & \\
\hline \multicolumn{5}{|l|}{ With whom do you chew Khat $(n=849)$} \\
\hline Family & $41(5.1)$ & $5(10.9)$ & $46(5.4)$ & \multirow{4}{*}{0.023} \\
\hline Relatives & $131(16.3)$ & $8(17.4)$ & $139(16.4)$ & \\
\hline Friends & $570(71.0)$ & $25(54.3)$ & $595(70.1)$ & \\
\hline Alone & $61(7.6)$ & $8(17.4)$ & $69(8.1)$ & \\
\hline \multicolumn{5}{|l|}{ Reasons of Khat chewing $(n=817)$} \\
\hline When feeling their stressed & $61(7.9)$ & $11(25.0)$ & $72(8.8)$ & \multirow{4}{*}{0.000} \\
\hline Anxiety & $25(3.2)$ & $2(4.5)$ & $27(3.3)$ & \\
\hline Need to change mood & $375(48.5)$ & $25(56.8)$ & $400(49.0)$ & \\
\hline Other reasons & $312(40.4)$ & $6(13.6)$ & $318(38.9)$ & \\
\hline
\end{tabular}

\section{Conclusions and Recommendations}

The use of Khat trend is increasing among higher education students in Jazan region, and it reflects the social and legal status of Khat in the community. Although Khat is illegal in Saudi Arabia, it is both socially acceptable and easily available and accessible by the majority of the population. Prevention and control programs need to use both high risk groups and general population interventions approaches. Law enforcement alone will not be sufficient to control and 
TABLE 4: Univariate and multivariate logistic regression analyses for Khat chewing related factors among study participants.

\begin{tabular}{|c|c|c|c|c|c|c|}
\hline \multirow{2}{*}{ Category } & \multicolumn{3}{|c|}{ Univariate } & \multicolumn{3}{|c|}{ Multivariate } \\
\hline & OR & 95\% C.I. & Sig. & OR & 95\% C.I. & Sig. \\
\hline \multicolumn{7}{|l|}{ Gender } \\
\hline \multicolumn{7}{|l|}{ Female (Ref.) } \\
\hline Male & 17.7 & $13.4-23.3$ & 0.000 & 10.11 & $4.88-17.38$ & 0.000 \\
\hline \multicolumn{7}{|l|}{ College type (Ref.) } \\
\hline \multicolumn{7}{|l|}{ Other scientific } \\
\hline Health-related & 0.70 & $0.57-0.86$ & 0.001 & 1.33 & $0.87-2.03$ & 0.184 \\
\hline Arts and humanities & 1.52 & $1.26-1.82$ & 0.000 & 1.67 & $1.13-2.47$ & 0.011 \\
\hline \multicolumn{7}{|l|}{ Academic year } \\
\hline \multicolumn{7}{|l|}{ First } \\
\hline Second & 1.61 & $1.28-2.02$ & 0.000 & 1.01 & $0.68-1.50$ & 0.965 \\
\hline Third & 1.55 & $1.23-1.96$ & 0.000 & 1.024 & $0.67-1.55$ & 0.911 \\
\hline Fourth & 1.42 & $0.98-2.06$ & 0.065 & 1.44 & $0.76-2.74$ & 0.268 \\
\hline \multicolumn{7}{|l|}{ Smoking status } \\
\hline \multicolumn{7}{|l|}{ No (ref.) } \\
\hline Yes & 20.69 & $16.96-25.25$ & 0.000 & 18.25 & $12.95-25.72$ & 0.000 \\
\hline \multicolumn{7}{|l|}{ Friend's smoking status } \\
\hline \multicolumn{7}{|l|}{ No (ref.) } \\
\hline Yes & 7.11 & $5.90-8.56$ & 0.000 & 1.243 & $0.84-1.83$ & 0.272 \\
\hline \multicolumn{7}{|l|}{ Friend's using Khat status } \\
\hline \multicolumn{7}{|l|}{ No (ref.) } \\
\hline Yes & 17.13 & $13.39-21.92$ & 0.000 & 4.43 & $2.78-7.37$ & 0.000 \\
\hline \multicolumn{7}{|l|}{ Father using Khat } \\
\hline \multicolumn{7}{|l|}{ No (ref.) } \\
\hline Yes & 1.77 & $(1.51-2.07)$ & 0.000 & 1.68 & $1.22-2.31$ & 0.001 \\
\hline \multicolumn{7}{|l|}{ Brother using Khat } \\
\hline \multicolumn{7}{|l|}{ No (ref.) } \\
\hline Yes & 2.56 & $(2.18-2.99)$ & 0.000 & 2.65 & $1.93-3.65$ & 0.000 \\
\hline \multicolumn{7}{|l|}{ Feeling Stressed } \\
\hline \multicolumn{7}{|l|}{ No (ref.) } \\
\hline Yes & 1.21 & $(1.03-1.42)$ & 0.020 & 0.97 & $0.64-1.46$ & 0.87 \\
\hline \multicolumn{7}{|l|}{ Feeling depressed } \\
\hline \multicolumn{7}{|l|}{ No (ref.) } \\
\hline Yes & 1.07 & $(0.90-1.26)$ & 0.431 & 1.38 & $0.91-2.08$ & 0.125 \\
\hline
\end{tabular}

${ }^{\circledR}$ Hosmer-Lemeshow goodness of fit test $\chi^{2}=3.181, P=0.923 ;{ }^{*}$ adjusted for other variables in the table.

prevent Khat chewing in Jazan community. A Multilevel, value based, comprehensive, and strategic long-term intervention plan is needed for more effective tools for preventive intervention and legal systems. The comprehensive plan may include, social interventions to change the community norms regarding Khat use which is crucial, geared by creating recreations alternatives and opportunities for youth, assessment and review of Faifa Development authority project for replacing Khat cultivation, reinforcement of law, and services programs for those at risk or need help to quit Khat use.

\section{Study Limitations}

Although Khat use is socially acceptable in Jazan region, we could not collect data about some associated behaviors like alcohol and sexual behaviors. Alcohol use is banned by law in Saudi Arabia and not tolerated socially and from Islamic religious point of view. The previously mentioned fact is applicable about sexual behaviors, and sometimes it is considered humiliating to ask such questions. The nonresponse rate is one anticipated issue. We controled for this by calculating the sample to overcome the expected response rate.

\section{Conflict of Interests}

The authors have no conflict of interests to declare.

\section{Funding}

This work was funded by the Substance Abuse Research Center (SARC), Jazan University, Saudi Arabia. 


\section{Acknowledgments}

The authors would like to thank Dr. Anwar Alahmar and Dr. Abdulwahab Ageeli from SARC for their efforts in supervising the data collection phase. The authors appreciate the efforts of the Education Directorate in Jazan Region, administrative staff, teachers, and school health professionals for the coordination and help with data collection.

\section{References}

[1] F. P. Grad, "The preamble of the constitution of the World Health Organization," Bulletin of the World Health Organization, vol. 80, no. 12, pp. 981-984, 2002.

[2] UNPIN. International Conference on Population and Development (ICPD). Cairo: ICPD, 1994, http://www.un.org/popin/ icpd2.htm .

[3] A. Mandil, A. Hussein, H. Omer, G. Turki, and I. Gaber, "Characteristics and risk factors of tabacco consumption among University of Sharjah students, 2005," Eastern Mediterranean Health Journal, vol. 13, no. 6, pp. 1449-1458, 2007.

[4] L.-A. Palen and J. D. Coatsworth, "Activity-based identity experiences and their relations to problem behavior and psychological well-being in adolescence," Journal of Adolescence, vol. 30, no. 5, pp. 721-737, 2007.

[5] R. Elsanosi, I. Bani, H. Ageely et al., "Socio-medical problem of the habituation of khat chewing in Jazan region in southern Saudi Arabia," European Journal of Scientific Research, vol. 63, no. 1, pp. 122-133, 2011.

[6] H. M. Ageely, "Prevalence of Khat chewing in college and secondary (high) school students of Jazan region, Saudi Arabia," Harm Reduction Journal, vol. 6, article 11, 2009.

[7] W. A. A. Milaat, I. A. Bani, H. M. Ageely et al., Assessment of Health Risk Factors and Social Problems Associated With Khat Use in Jazan Region, King Abdulaziz University, Jazan, Saudi Arabia, 2006.

[8] T. Baasher, "The use of Khat: a stimulant with regional distribution," in Drug Problems in the Sociocultural Context: A Basis For Policies and Programme Planning, A. GEaA, Ed., WHO, Geneva, Switzerland, 1980.

[9] R. A. Heacock and J. E. Forrest, "Khat," Canadian Journal of Pharmaceutical Sciences, vol. 9, no. 3, pp. 64-66, 1974.

[10] T. Baasher, "The use of drugs in the Islamic World," British Journal of Addiction, vol. 76, no. 3, pp. 233-243, 1981.

[11] W. Luqman and T. S. Danowski, "The use of khat (Catha edulis) in Yemen. Social and medical observations," Annals of Internal Medicine, vol. 85, no. 2, pp. 246-249, 1976.

[12] J. P. Hes, "The use of Catha edulis among Yemenite Jews," Harefuah, vol. 78, no. 6, pp. 283-284, 1970.

[13] H. Halbach, "Medical aspects of the chewing of khat leaves," Bulletin of the World Health Organization, vol. 47, no. 1, pp. 2129, 1972.

[14] J. G. Kennedy, J. Teague, W. Rokaw, and E. Cooney, "A medical evaluation of the use of qat in North Yemen," Social Science and Medicine, vol. 17, no. 12, pp. 783-793, 1983.

[15] A. Alem and T. Shibre, "Khat induced psychosis and its medicolegal implication: a case report," Ethiopian Medical Journal, vol. 35, no. 2, pp. 137-141, 1997.

[16] G. Yousef, Z. Huq, and T. Lambert, "Khat chewing as a cause of psychosis," British journal of hospital medicine, vol. 54, no. 7, pp. 322-326, 1995.
[17] M. Odenwald, F. Neuner, M. Schauer et al., "Khat use as risk factor for psychotic disorders: a cross-sectional and casecontrol study in Somalia," BMC Medicine, vol. 3, article 5, 2005.

[18] C. Pantelis, C. G. Hindler, and J. C. Taylor, "Use and abuse of khat (Catha edulis): a review of the distribution, pharmacology, side effects and a description of psychosis attributed to khat chewing," Psychological Medicine, vol. 19, no. 3, pp. 657-668, 1989.

[19] S. P. Gough and I. B. Cookson, "Khat-induced schizophreniform psychosis in UK," The Lancet, vol. 1, no. 8374, p. 455, 1984.

[20] A. J. Giannini and S. Castellani, "A manic-like psychosis due to khat (Catha edulis Forsk.)," Journal of Toxicology, vol. 19, no. 5, pp. 455-459, 1982.

[21] M. Dhadphale, H. N. K. Arap Mengech, and S. W. Chege, "Miraa (Catha edulis) as a cause of psychosis," East African Medical Journal, vol. 58, no. 2, pp. 130-135, 1981.

[22] A. K. N. Laswar and H. Darwish, "Prevalence of cigarette smoking and khat chewing among Aden university medical students and their relationship to BP and body mass index," Saudi Journal of Kidney Diseases and Transplantation, vol. 20, no. 5, pp. 862866, 2009.

[23] Z. A. Zein, "Polydrug abuse among Ethiopian university students with particular reference to khat (Catha edulis)," Journal of Tropical Medicine and Hygiene, vol. 91, no. 2, pp. 71-75, 1988.

[24] A. O. Ihunwo, F. I. B. Kayanja, and U. B. Amadi-Ihunwo, "Use and perception of the psychostimulant, khat (Catha edulis) among three occupational groups in south western Uganda," East African Medical Journal, vol. 81, no. 9, pp. 468-473, 2004.

[25] A. Alem, D. Kebede, and G. Kullgren, "The prevalence and socio-demographic correlates of khat chewing in Butajira, Ethiopia," Acta Psychiatrica Scandinavica, vol. 99, Supplement, no. 397, pp. 84-91, 1999.

[26] I. Dhaifalaha and J. Šantavý, "Khat habit and its health effect. A natural amphetamine," Biomedical papers, vol. 148, no. 1, pp. 11-15, 2004.

[27] M. Odenwald, N. Warfa, K. Bhui, and T. Elbert, "The stimulant khat-Another door in the wall? A call for overcoming the barriers," Journal of Ethnopharmacology, vol. 132, no. 3, pp. 615619,2010

[28] H. J. B. H. M. Dupont, C. D. Kaplan, H. T. Verbraeck, R. V. Braam, and G. F. Van De Wijngaart, "Killing time: drug and alcohol problems among asylum seekers in the Netherlands," International Journal of Drug Policy, vol. 16, no. 1, pp. 27-36, 2005.

[29] Y. Gelaw and A. Haile-Amlak, "Khat chewing and its sociodemographic correlates among the staff of Jimma University," Ethiopian Journal of Health Development, vol. 18, no. 3, pp. 179184, 2004.

[30] F. Wedegaertner, H. Al-Warith, T. Hillemacher et al., "Motives for khat use and abstinence in Yemen: a gender perspective," BMC Public Health, vol. 10, article 735, 2010. 


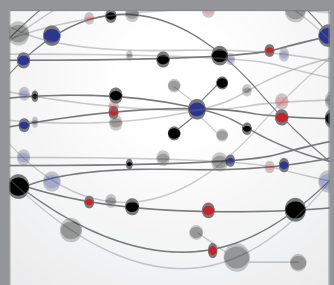

The Scientific World Journal
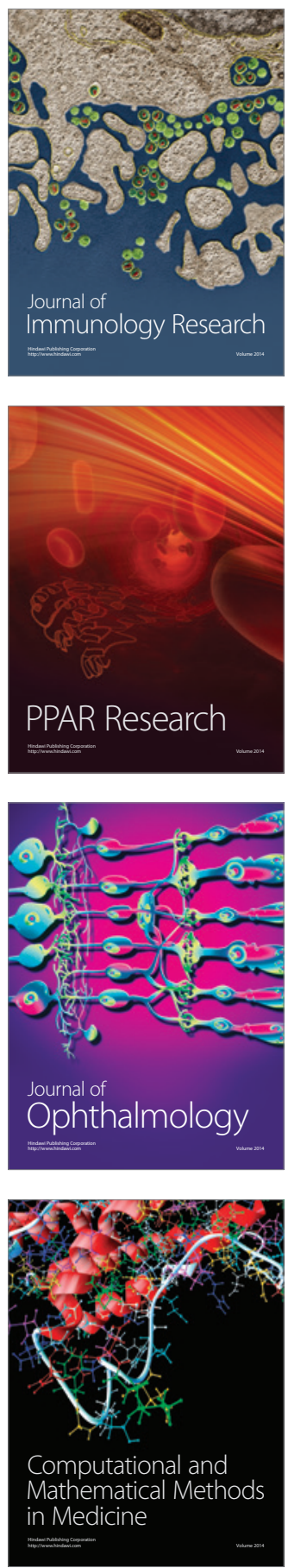

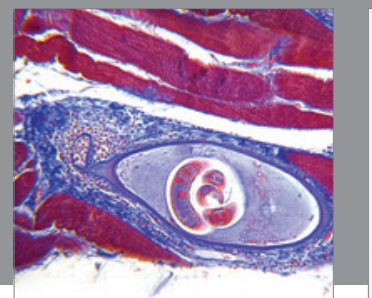

Gastroenterology

Research and Practice
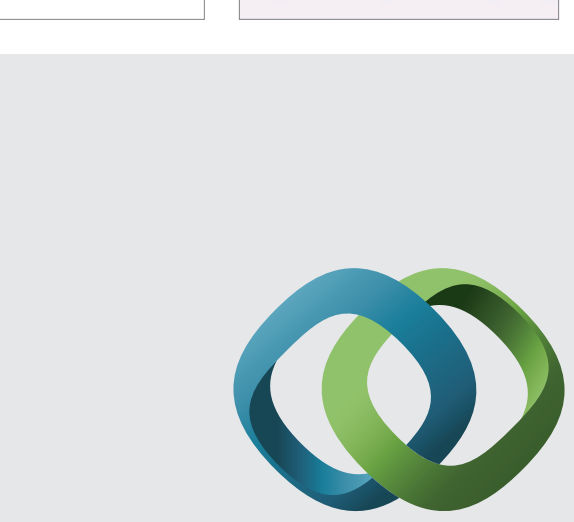

\section{Hindawi}

Submit your manuscripts at

http://www.hindawi.com
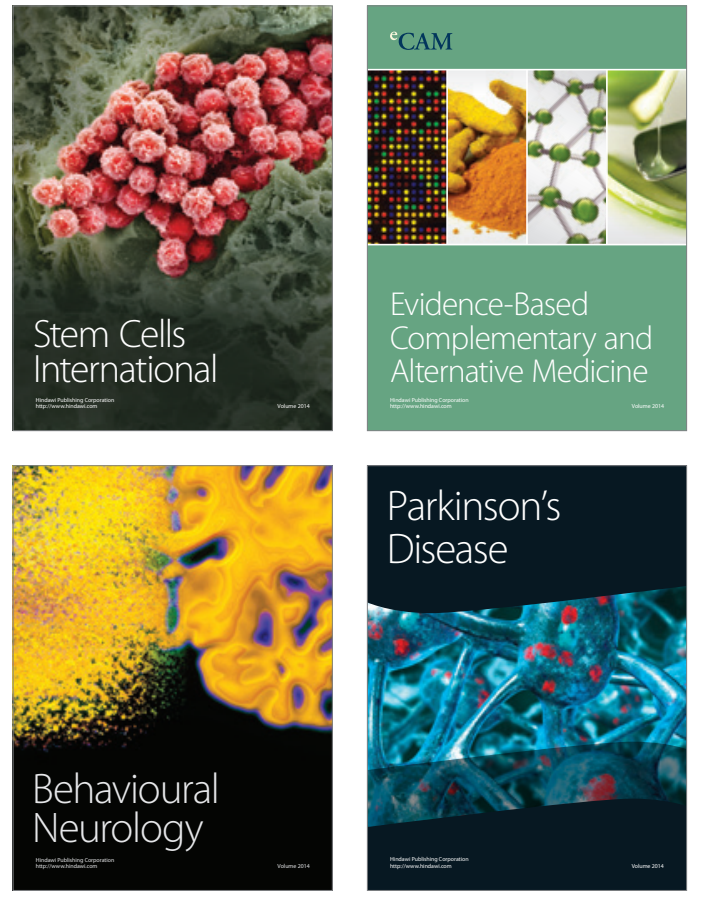
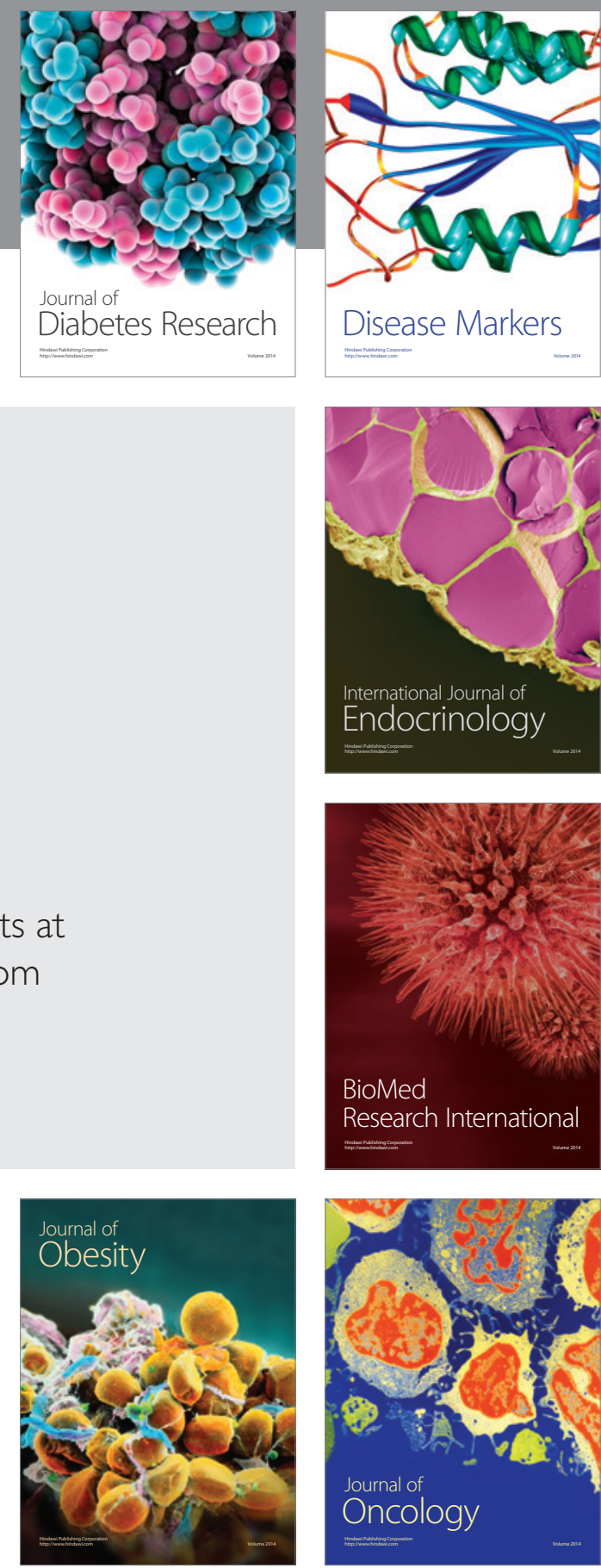

Disease Markers
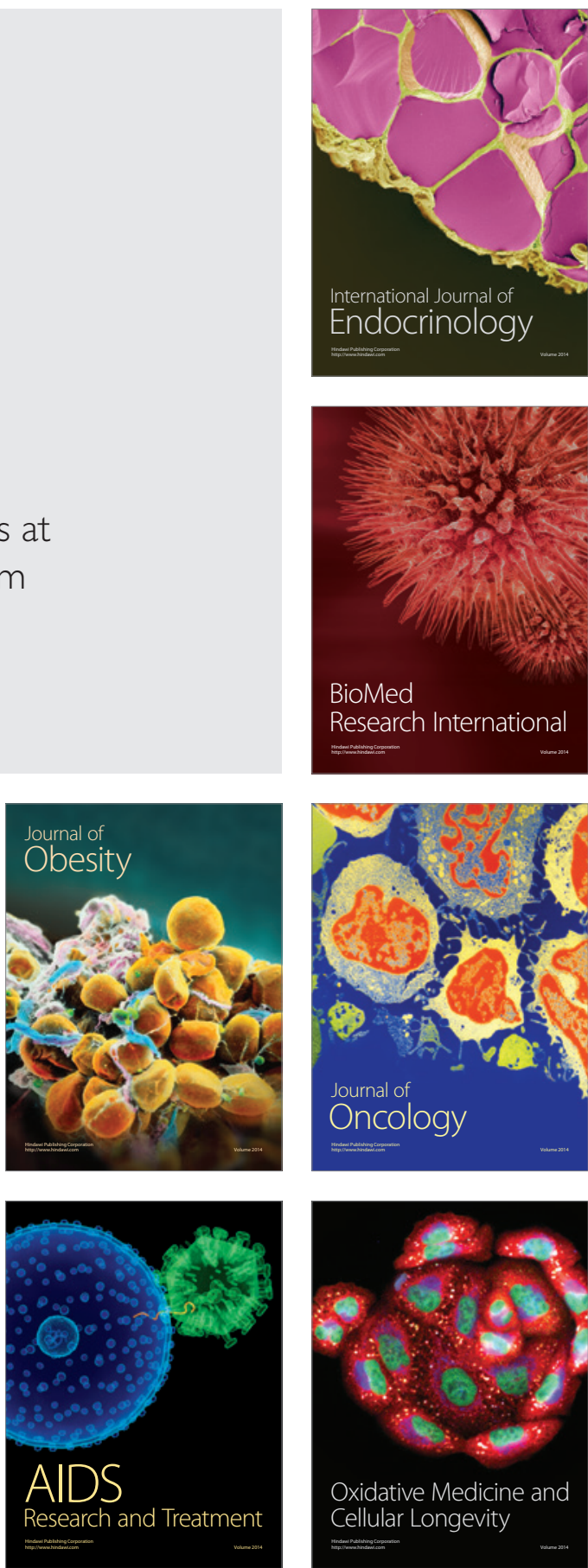